\title{
The psychological burden of an initially unexplained illness: patients with sternocostoclavicular hyperostosis before and after delayed diagnosis
}

Willem A van der Kloot ${ }^{1 *}$, Neveen AT Hamdy², Laurian CS Hafkemeijer ${ }^{1}$, Femke MC den Dulk', Sadhna A Chotkan ${ }^{2}$, Arnold AP van Emmerik ${ }^{3}$, Ad A Kaptein ${ }^{4}$

\begin{abstract}
Background: Sternocostoclavicular hyperostosis $(\mathrm{SCCH})$ is a rare, debilitating, chronic inflammatory disorder of the anterior chest wall due to a chronic sterile osteomyelitis of unknown origin. SCCH is largely underdiagnosed and often misdiagnosed. In individual cases it can remain unrecognized for years. The purpose of this study is twofold. Firstly, to evaluate the psychological condition of SCCH patients, both in the sometimes quite extended prediagnostic period between first manifestations and confirmed diagnosis of the disease, and in the current situation. Secondly, to investigate the relationships between the pre-diagnostic and the current psychological conditions of confirmed SCCH patients.
\end{abstract}

Methods: Structured interviews were held with 52 confirmed SCCH patients. Questionnaires were included to assess posttraumatic stress symptoms, social support, aspects of pain, illness perceptions, self-reported health status, and quality of life.

Results: SCCH patients reported stronger posttraumatic stress symptoms, more unfavorable illness perceptions, lower health status, and poorer quality of life than healthy individuals and patients with other diseases or traumatic experiences. Psychological distress in the pre-diagnostic period was associated with unfavorable conditions in the current situation.

Conclusion: SCCH is an illness with serious psychological consequences. Psychological monitoring of patients with unexplained complaints is recommended as long as a diagnosis has not been reached.

\section{Background}

Patients who suffer from rare diseases often encounter difficulties that victims of more common disorders are spared. Fewer health care providers have sufficient knowledge and experience to handle a rare disease and usually no or much fewer therapeutic options are available. Moreover, lack of awareness of the clinical manifestations of a rare disease may lead to diagnostic delay, failure of diagnosis, and misdiagnosis. Recently, these problems have been documented in a detailed report by the European Organisation of Rare Diseases, which was

\footnotetext{
* Correspondence: w.a.van.der.kloot@umail.leidenuniv.nl

'Institute of Psychology, Leiden University, The Netherlands

Full list of author information is available at the end of the article
}

summarized in The Lancet [1,2]. In two surveys of a total of 12,000 patients with 16 different rare diseases, it was found that, with the exception of cystic fibrosis, $25 \%$ of the patients had to wait more than 3 years before the correct diagnosis was established, and that $41 \%$ were initially misdiagnosed, including $7 \%$ who were told that their symptoms were psychological or psychiatric. Eighteen percent of the patients had to find answers on their own to obtain the correct diagnosis. In $19 \%$ of the patients, diagnostic delay led to loss of confidence in the health-care system. Eighteen percent experienced rejection by a health-care professional because of disease complexity or associated symptoms. 
The EURORDIS findings are paralleled by the results from a study of our own research group on patients with sternocostoclavicular hyperostosis $(\mathrm{SSCH})$, a rare inflammatory disease of the axial skeleton [3]. Fifty percent of our patients had to wait between 3.5 and 36 years for a correct diagnosis, $40 \%$ were initially misdiagnosed, $4 \%$ were told that their symptoms were psychological, and $35 \%$ had sometimes felt rejected by doctors or nursing staff. In $23 \%$ the correct diagnosis was only established after the patients obtained information from sources outside their regular medical circuit.

$\mathrm{SCCH}$ is a rare chronic, inflammatory disorder of the axial skeleton, caused by a chronic sterile osteomyelitis with a predilection for the sternum, the medial ends of the claviculae, and the upper ribs. The most common clinical manifestations of $\mathrm{SCCH}$ include redness and (usually painful) swelling in the sternoclavicular region often associated with restricted and painful mobility of the adjacent shoulder(s). Thirty to fifty percent of the patients may develop pustulosis palmoplantaris, a chronic sterile inflammation characterized by sterile pustules on the palms of the hand or the soles of the feet, though not necessarily simultaneously with the bone manifestations.

SCCH was first described as a separate entity in 1974 in Japan and in 1975 in Germany [4,5]. In 1987, Chamot et al. coined the term SAPHO (Synovitis, Acne, Pustulosis, Hyperostosis, Osteitis) for a syndrome in which $\mathrm{SCCH}$ was associated with generalized joint and skin manifestations [6]. The literature shows that $\mathrm{SCCH}$ is an ill-known syndrome that may remain unrecognized for years [7-10] and that it is largely underdiagnosed due to a lack of awareness among physicians for the disorder [9-14]. Patients with SCCH have been described to go through a "diagnostic odyssey" [12, p. 209] before a correct diagnosis was obtained $[15,16]$ and some dramatic examples were described of cases that were initially misdiagnosed and treated incorrectly $[16,17]$. Recently, we have shown that the duration of the interval between the first manifestations of SCCH and the establishment of its diagnosis had some serious negative psychological and socioeconomic consequences for SCCH patients [3].

\section{The pre-diagnostic period}

During the often quite extended interval between the first manifestations of a rare disease and its correct diagnosis, patients live in a diagnostic vacuum as long as their symptoms remain medically unexplained and lack a descriptive diagnostic label. This situation, as Nettleton, Watt, O'Malley, and Duffey [18] demonstrated, made patients fear that their illness was "all in the mind" (p. 207) and "not legitimate" (p. 207). It made patients feel "marginalized by doctors" (p. 206), and made them represent their illness in terms of "chaos narratives" (p. 206) characterized by "confusion and uncertainty" (p. 206) and "a merry-go-round of hope and despair" (p. 206). Such strong feelings suggest that a prolonged pre-diagnostic period is stressful and traumatic and may produce serious repercussions on the mental health of the patients involved, for instance in the form of post-traumatic stress symptoms.

\section{Post-traumatic stress}

The relationship between post-traumatic stress (PTS) and physical illness has been documented in a variety of studies. PTS following violent or life-threatening experiences is often construed as a cause of or contributor to physical illness $[19,20]$ although there is reason for caution with this interpretation [21]. Moreover, it has been observed that illness itself can be a traumatic condition that produces PTS. PTS was observed in women suffering from breast cancer in several stages [22-24], in patients after bone marrow transplantation for cancer [25], and among patients who underwent acute medical treatment in Intensive Care Units [26]. The latter study suggested that "the presence of traumatic memories [italics added] is one of the most relevant aspects for the development of PTSD-related symptoms" [26, p. 671]. Clinical levels of PTS were also found in women after spontaneous abortion [27], after abortion for fetal abnormality [28], after elective surgical abortion [29], and after childbirth [30,31]. For some women, the intense pain and feelings of helplessness during childbirth constitute a severely traumatic experience to which they may react with PTS [30,32]. In these cases (i. e. cancer, ICU-hospitalization, abortion, childbirth), it appears that the feelings and memories associated with the illness or violent bodily experience are the traumatic agents that produce or facilitate PTS.

In the interval between first symptoms and diagnosis, $\mathrm{SCCH}$-patients experience pain, swelling, and/or restricted mobility of the shoulder girdle that are either not medically explained and thus remain untreated, or are incorrectly explained and consequently unsuccessfully treated. We hypothesized that in this situation, which may be worsened by feeling rejected by health professionals and others in the social environment, patients may develop symptoms of PTS.

\section{Social support}

Several studies have shown that coping with stress and traumatic events is positively influenced and moderated by the social support individuals receive or perceive [25,33-35]. Although some other studies [31,36] did not find an effect of social support on PTS, we hypothesized that social support will have a beneficial effect on PTS in $\mathrm{SCCH}$-patients.

\section{The current situation}

As $\mathrm{SCCH}$ is a chronic disease, a definitive cure cannot be achieved when the diagnosis is finally established. 
Treatment is mainly aimed at pain relief and control of the local inflammatory changes. However, even when the inflammatory manifestations are controlled, patients may retain some residual disability in the form of chronic pain and limited mobility of the shoulder girdle due to irreversible, degenerative changes in the structure of the affected bones. To better understand how $\mathrm{SCCH}$ may affect the life of patients with a confirmed $\mathrm{SCCH}$ diagnosis, we compared their quality of life (QOL), illness perceptions, and self-reported health status to those of patients with other diseases.

\section{Objectives}

Our first objective was to evaluate the psychological condition of $\mathrm{SCCH}$ patients and the extent and seriousness of their problems both in the interval between first manifestations and diagnosis of the disease, and in the current situation, after the diagnosis had been established for some time. Our second objective was to investigate the relationship between the pre-diagnostic condition and the present-day situation of patients with $\mathrm{SCCH}$. We expected that problems such as PTS in the pre-diagnostic period may have repercussions on QOL, illness perceptions, and self-reported health status at a later stage in the course of the illness. Moreover, because several studies have shown social support to have a positive effect on QOL $[37,38]$, we tested the hypothesis that social support in the pre-diagnostic period is related to (perceived) physical and mental health at the time of the study.

\section{Materials and methods}

The study was initiated and conducted by the Psychology Institute of Leiden University. This institute does not require ethical approval and does not comprise an ethical commission. Design and execution of the study followed the ethical standards of the American Psychological Association. The study was supported by the Dutch SCCH Patient Association http://www.scch.nl, which helped to recruit the majority of patients from its members. Most patients were also under regular clinical control of one of the authors (NATH) at the Department of Endocrinology and Metabolic Diseases of the Leiden University Medical Center (LUMC), a tertiary referral center for patients with $\mathrm{SCCH}$.

\section{Patients}

Fifty-seven patients with a definitive diagnosis of $\mathrm{SCCH}$ were invited to participate in this study. Fifty-two of them responded positively and were interviewed in their homes by one of three trained interviewers: two psychology Master students and one final-year medical student. We estimated that these 52 respondents encompassed the majority of Dutch patients with a diagnosis of $\mathrm{SCCH}$ and were representative of this population. The patients were contacted by telephone and if they agreed to participate, a date and time were set for the interview. Written informed consent was obtained from all patients prior to the start of the interviews.

\section{Interviews}

Interviews consisted of a structured set of questions on gender, age, age at the time of the first manifestations of $\mathrm{SCCH}$, education, employment, and several aspects of the patient's medical and psychological condition both in the pre-diagnostic period and in the present situation. The patients were also interviewed about their trajectories in the health care system between onset of the disease and confirmed diagnosis (those results have been published elsewhere [3]).

The interviewers asked most questions verbally. The responses were written on protocol sheets and (after permission) were registered on a voice recorder. During the interview the respondents also completed several questionnaires. To describe their condition in the prediagnostic period, the patients were asked to localize their complaints on drawings from the Dutch language version of the McGill Pain Questionnaire (MPQ-DLV) [39] and were presented with Dutch versions of the Revised Impact of Event Scale (IES-R) [40] and the Social Support Inventory (SSI) [41]. With regard to their present situation, the patients filled out the complete MPQ-DLV, the Dutch version of the Brief Illness Perception Questionnaire (B-IPQ) [42], and the MOS Short-Form General health Survey (SF-20) [43].

\section{Questionnaires}

The IES-R measures symptoms of PTS by means of 22 statements (e.g. "In the period when it was not yet clear that my complaints were due to $\mathrm{SCCH}$, I found it difficult to concentrate") with four response categories "never", "rarely", "sometimes", and "often", which, using the original scoring system, were coded as $0,1,3$, and 5 . From these items scores were computed on the three subscales intrusion, avoidance, and hyperarousal. These subscales were subsequently combined to form the IESR-total score.

Five emotional impact statements ("my complaints made me desperate", "my complaints felt like a drama", "I was very concerned about my complaints", "I was very frightened about my complaints", and "I was very depressed about my complaints") were presented with response categories $0=$ never, $1=$ rarely, $2=$ sometimes, and 3 = often.

The SSI contains 20 questions (e.g. "In the period when it was not yet clear that your complaints were due to $\mathrm{SCCH}$, how often did somebody cheer you up?") with 
response categories (1) much too infrequently, (2) somewhat too infrequently, (3) just right, (4) somewhat too often, and (5) far too often. The 5 and 4 responses were recoded into 1 and 2, respectively, yielding scores that measure satisfaction with support. Four subscales were computed: emotional support, informative support, instrumental support, and social companionship, which also were aggregated into SSI-total.

The MPQ-DLV consists of four parts. The first part shows two drawings of a nude, androgynous person, seen from the front and from the back, on which the respondents indicated the regions where they felt pain or had other complaints. The drawings were scored by superimposing a $0.5 \times 0.5 \mathrm{~cm}$ grid and counting the number of grid cells marked by the respondent. This resulted into four variables: frontal-complaints-first and dorsal-complaints-first concerning the first, prediagnostic, manifestations of $\mathrm{SCCH}$, and frontal-complaints-now and dorsal-complaints-now for the present situation. The second part consists of questions regarding pain from which we selected "Do you ever feel pain?" with response categories (1) never, (2) yes, but the pain comes in waves and disappears between the waves, (3) yes, the pain is always present but its intensity varies, and (4) yes, the pain is always present and has always the same intensity. The third part consists of two $100 \mathrm{~mm}$ visual analogue scales (VAS) with endpoints "no pain at all" and "unbearable pain". On the first VAS, the respondents rated the intensity of their current pain (VASnow). On the second VAS they rated the intensity of their pain when it was least intense (VASmin) and when it was most intense (VAS$\max )$. The last part of the MPQ-DLV consists of 20 sets of three or four pain describing adjectives. In each set that contained adjectives that were applicable to their pain, respondents marked the one adjective that best described their pain. The sets of adjectives describe three different qualities of pain: sensory (e.g. burning, sharp, pinching), affective (e.g. exhausting, fearful), and evaluative (e.g. annoying, unbearable). From the marked adjectives four pain rating indices (PRIS, PRIA, PRIE, PRIT) were constructed that indicate the intensities of the sensory, affective, and evaluative qualities of pain, respectively, as well as the total intensity.

The B-IPQ contains eight questions (e.g. "How long do you think your illness will continue?") each measuring a perception of one's illness. The perceptions (called dimensions) are labeled consequences, time-line, personal control, treatment control, identity, concern, understanding, and emotional response. Each response is measured on a scale from 0 to 10 with the appropriate labels.

The SF-20 contains 20 questions that concern health status and quality of life. The items (e.g. "Are you restricted in bending, lifting, or stooping?") are summarized by six dimensions: physical functioning, role fulfillment, social functioning, mental health, perceived health, and physical pain. Higher scores indicate more favorable conditions.

\section{Analysis}

Two of the authors categorized the responses to the open questions. Interobserver agreement was "good" to "perfect" with Kappa's between 0.70 and 1.00 (quartiles: $0.83,0.94$, and 0.98). For the questionnaire data, Cronbach's alphas, means, and standard deviations (SD) were computed. Means of the present sample were compared with means obtained from samples in other studies, using analysis of variance (ANOVA) and Bonferroni comparisons. Relationships among variables were studied by means of Pearson product moment correlations and various multivariate techniques, notably, multiple regression, principal component analysis, and canonical correlation analysis.

\section{Results}

The respondent group consisted of 46 women $(88.5 \%)$ and 6 men (11.5\%) whose ages varied between 24 and 79 years (median: 56 yrs). The oldest complaint dated back 49 years, the most recent one 2 years (median 11 yrs). The age at which the first complaints arose (agefirst) ranged from 15 to 72 years (median $41.5 \mathrm{yrs}$ ). The time interval between the patient's first consultation and establishment of the diagnosis varied from 1 month to 36 years. In 4 cases, the complaints started before 1976, that is, earlier than, or at the same time as the first publications on $\mathrm{SCCH}$; therefore those patients could not possibly have been diagnosed before 1976. For those patients we have used 1976 as the year of first consultation. The maximum interval length then becomes 24 years with a mean of $5.6 \pm 5.9$ years and a median of 3.5 years. The $25 \%$ quartile was exactly 1 year; the $75 \%$ quartile was equal to 8.75 years. The earliest $\mathrm{SCCH}$ diagnosis among our respondents was established in 1988. The most recent diagnosis was confirmed in 2007, the year our study was run. The median was reached in 2000; the $25 \%$ and $75 \%$ quartiles were in 1995 and 2003, respectively

\section{The pre-diagnostic interval}

The frontal complaints at first manifestation of $\mathrm{SCCH}$ ranged from 0 to 32 marked grid-cells (possible range: 0 - 111; mean $=4.58 ; \mathrm{SD}=6.65)$. The dorsal complaints at first manifestations ranged from 0 to 50 (possible range: $0-134 ;$ mean $=3.15 ; \mathrm{SD}=8.65$ ). Sixty-one percent of the frontal and $59 \%$ of the dorsal markings, respectively, were in the upper thoracic and shoulder regions. 


\section{Table 1 Frequencies and percentages of coded responses to the open questions concerning the pre-diagnostic}

\section{interval}

During the interval before diagnosis, were you able to carry on with your normal work and other activities?

No

45

Yes

How did you feel during the interval before diagnosis?

Worried, frightened

Depressed, desperate, overwhelmed by disease

Misunderstood, not taken seriously, angry

Normal, matter of fact

How did your environment react?

Worried, startled

Helpful, empathic, supportive

Empathy at first, later less

Normal, no empathy, unbelief

Patient did not tell environment about disease

Did your environment support you?

Never

Sometimes, little support

Gave much support

Support only from close family

Patient did not need support

What was the extent of the received support?

No support

Little support, sometimes support

Much support

Did others doubt that you were ill?

Never, always taken seriously

No doubt in close environment, rest doubted

Doubt, did not think complaints were important

Patient did not consider herself ill

Environment did not know about disease

Did you yourself sometimes doubt that you were ill?

No

Sometimes

Did others think your complaints were psychological, "all in the mind"?

No

Yes, disease was psychological

Affectation

Did you yourself think that your complaints were psychological, "all in the mind"?

No

Sometimes

Did you sometimes feel guilty about your illness?

No

Sometimes

Often

Were you sometimes not taken seriously by health-care providers?

No, always taken seriously

Yes, by General Practitioner (GP)

Yes, by some doctors (GP or specialist)

Yes, by hospital staff

How often were you not taken seriously by health-care providers?

Never

Sometimes

Often
$86.5 \%$

$13.5 \%$

$48.1 \%$

$23.1 \%$

$17.3 \%$

$11.5 \%$

28.9\%

$38.5 \%$

$3.9 \%$

$19.2 \%$

$7.7 \%$

$5.8 \%$

$9.6 \%$

$46.2 \%$

$32.7 \%$

$5.8 \%$

$11.5 \%$

$25.0 \%$

$63.5 \%$

$44.2 \%$

$23.1 \%$

$25.0 \%$

$1.9 \%$

$5.8 \%$

$82.7 \%$

$17.3 \%$

$67.3 \%$

$28.8 \%$ 
Table 1 contains the frequencies and percentages of the responses to the open questions concerning the period between first symptoms and definitive diagnosis of $\mathrm{SCCH}$. The majority of the respondents were seriously affected by their disease, as $86.5 \%$ was no longer able to perform their normal work or other activities, and $88.5 \%$ felt worried, depressed, or misunderstood. Although $78.9 \%$ of the patients reported support from their environment, at least from their close relatives, 48.1\% experienced that others had doubts about their illness and $32.6 \%$ reported that others believed their illness to be psychological or a form of affectation. Moreover, $21.2 \%$ of the patients themselves sometimes doubted they were really ill and thought their complaints might be psychological. Some forty percent of the respondents felt guilty, of whom $34.6 \%$ often. Twothirds $(67.3 \%)$ reported that they (sometimes or often) had not been taken seriously by their health-care providers, among whom their own general practitioners. These data confirm all the major themes (uncertainty, despair, guilt, "it is all in the mind", marginalization by doctors) that were found among the patients with an unexplained illness in the study by Nettleton, et al. [18].

The five statements "desperate", "drama", "concerned", "frightened", and "depressed", which could be endorsed on a scale from 0 (never) to 3 (often), had means and SDs of, respectively, $1.4 \pm 1.19,1.29 \pm 1.09,1.71 \pm 1.05$, $1.08 \pm 1.05$, and $1.65 \pm 1.08$. The mean and SD of the scales after summation was $7.13 \pm 4.78$. The Cronbach Alpha reliability coefficient was .922. Thirteen (25\%), eight $(15.4 \%)$, thirteen $(25 \%)$, five $(9.6 \%)$, and thirteen (25\%) respondents gave the response "often" to the five questions. These results indicate that having an (initially) unexplained illness has serious psychological mental consequences for a substantial number of patients.

\section{PTS symptoms}

Table 2 contains the means, SDs and ranges of our respondents' scores on the three subscales and the total scale of the IES-R. For comparison we have added the means and SDs of two other Dutch samples: 435 women who recently gave birth [32] and 191 women who had their pregnancies terminated because of fetal abnormality [28].

ANOVAs showed significant overall differences (see Table 2) among the means of the different samples. In order to study differences among the means of the separate samples, we performed 3 post hoc Bonferroni comparisons for each scale using $\alpha=.05 / 3$ (two-tailed) and critical $t$-value $= \pm 2.401(d f=675)$. On all IES-R scales and IES-R-total, the means of the scores of $\mathrm{SCCH}$ patients were significantly greater $(\mathrm{p}<.0001)$ than those of the other groups.

\section{Social support}

Table 3 contains the means and SDs of the SCCH patients on the scales of the SSI. Where the possible scores of the SSI subscales range from 5 to 15 and the SSI-total from 20 to 60 , the observed means of the $\mathrm{SCCH}$ patients are located in the upper regions of the possible scores, which means that our respondents have felt on average rather satisfied with the experienced degree of social support. This corroborates the data on support in Table 1. As we could not find means and SDs of other samples in the literature, we cannot compare our SSI data with those of other studies.

To test the - directional - hypothesis that social support has a negative association with PTS symptoms, we computed bivariate correlation coefficients between the four IES-R scales and the five SSI scales and used onetailed tests of significance. All SSI scales had significant negative correlations with hyperarousal and three SSI scales (SSI-emotional, SSI-instrumental, and SSI total) had significant negative correlations with IES-R total (see Table 3). The latter three correlations are explained by the correlations between the SSI scales and hyperarousal, as all other coefficients were not significant. Thus, it appears that hyperarousal (i.e. irascibility, hypervigilance, concentration and sleeping problems) is tempered by all four modes of social support. However, all correlation coefficients are rather small. The SSI scale with the highest correlation (SSI instrumental) explains

Table 2 Mean \pm SD, number of items, range of observed scores, Cronbach's $\alpha$, and $F$-values of the subscales of the Impact of Event Scale (Revised) observed in the present sample and in two comparison samples (means with equal upper case superscripts are not significantly different)

\begin{tabular}{lllll}
\hline $\begin{array}{l}\text { IES-R scale } \\
\text { \# of items; range; } \boldsymbol{\alpha})\end{array}$ & $\begin{array}{l}\text { SCCH patients } \\
\mathbf{n = 5 2}\end{array}$ & $\begin{array}{l}\text { Childbirth data } \\
\mathbf{n}=\mathbf{4 5 3}\end{array}$ & $\begin{array}{l}\text { Pregnancy termination data } \\
\mathbf{n}=\mathbf{1 9 1}\end{array}$ & $\begin{array}{l}\boldsymbol{F} \text {-value } \\
\boldsymbol{d f}=\mathbf{2}, \mathbf{6 7 5}\end{array}$ \\
\hline $\begin{array}{l}\text { Intrusion } \\
(8 ; 0-40 ; .866)\end{array}$ & $16.12^{\mathrm{A}} \pm 9.76$ & $7.24^{\mathrm{C}} \pm 6.8$ & $9.35^{\mathrm{B}} \pm 8.02$ & $34.959^{* *}$ \\
$\begin{array}{l}\text { Avoidance } \\
(8 ; 0-36 ; .854)\end{array}$ & $16.83^{\mathrm{A}} \pm 9.69$ & $2.13^{\mathrm{C}} \pm 4.2$ & $5.64^{\mathrm{B}} \pm 7.54$ & $153.220^{* *}$ \\
$\begin{array}{l}\text { Hyperarousal } \\
(6 ; 0-30 ; .843)\end{array}$ & $12.50^{\mathrm{A}} \pm 8.27$ & $3.23^{\mathrm{C}} \pm 4.3$ & $4.78^{\mathrm{B}} \pm 6.46$ & $70.036^{* *}$ \\
$\begin{array}{l}\text { Total } \\
(22 ; 2-96 ; .931)\end{array}$ & $45.45^{\mathrm{A}} \pm 24.73$ & $12.61^{\mathrm{C}} \pm 13.0$ & $19.78^{\mathrm{B}} \pm 19.48$ & $99.230^{* *}$ \\
\hline
\end{tabular}

${ }^{\mathrm{a}}$ Olde et al. [32]; ${ }^{\text {b}}$ Korenromp et al. [28]; ${ }^{* *}=p<.0001$. 
Table 3 Mean \pm SD, number of items, observed and possible range, Cronbach's $\alpha$, and correlations with hyperarousal and IES-R-total of the Social Support Inventory scales

\begin{tabular}{lccrrrr}
\hline & & & & & \multicolumn{2}{c}{ Correlations with } \\
\cline { 5 - 7 } Scale name & Mean \pm SD & Number of items & Range of scores ${ }^{\mathbf{a}}$ & Cronbach's $\boldsymbol{\alpha}^{\text {hyperarousal }}$ & IES-R-total \\
\hline Emotional support & $12.70 \pm 2.43$ & 5 & $5-15$ & .842 & $-.294\left(.018^{\mathrm{b}}\right)$ & $-.250\left(.039^{\mathrm{b}}\right)$ \\
Instrumental support & $12.02 \pm 2.60$ & 5 & $5-15$ & .742 & $-.380\left(.003^{\mathrm{b}}\right)$ & $-.265\left(0.30^{\mathrm{b}}\right)$ \\
Social companionship & $12.17 \pm 2.85$ & 5 & $5-15$ & .844 & $-.288\left(.020^{\mathrm{b}}\right)$ & $-.206\left(.074^{\mathrm{b}}\right)$ \\
Informative support & $12.39 \pm 2.54$ & 5 & $5-15$ & .782 & $-.236\left(.048^{\mathrm{b}}\right)$ & $-.166\left(.123^{\mathrm{b}}\right)$ \\
SSI total & $49.29 \pm 9.10$ & 20 & $20-60$ & .931 & $-.343\left(.007^{\mathrm{b}}\right)$ & $-.253\left(.037^{\mathrm{b}}\right)$ \\
\hline
\end{tabular}

${ }^{\mathrm{a}}$ The ranges of the observed scores were equal to the ranges of the possible scores. ${ }^{\mathrm{b}}$ One-tailed probability.

only $14.4 \%$ of hyperarousal; this amount cannot be increased by adding the three other SSI scales as predictors, because they are highly collinear (see below).

Principal component factor analysis of the three IES-R subscales and the subscales of the SSI yielded two factors that together explained $78 \%$ of the variance. After Oblimin-rotation, one factor coincided with the three IES-R subscales and the other with the SSI subscales. Factor scores of the two factors completely coincided with, respectively, IES-R-total $(r=.999)$ and SSI-total $(r=1.000)$. The two oblique factors were almost perpendicular, with a correlation of -.244 (6\% common variance), which is barely significant at $\alpha=.05$, one-tailed. Therefore, the hypothesis that social support has a beneficial effect on PTS is only weakly supported in the present study.

Product-moment correlations were computed between age-first, frontal-complaints-first, dorsal-complaints-first, and diagnostic delay, on the one hand, and the four IES-R and five SSI scales on the other hand. None of the correlations with the IES-R scales were significant. Age at first manifestations and diagnostic delay correlated significantly with emotional support (resp. $r=$ $.374, p=.007 ; r=-358, p=.010)$ and with social companionship (resp. $r=.327, p=.019 ; r=-.347, p=.013$ ). Diagnostic delay also had significant correlations with SSI informative support $(r=-.342, p=.014)$ and SSI total $(r=-.356, p=.010)$. The positive correlations between age-first and the two SSI scales, might be explained by the fact that the respondents who fell ill at an older age had a more elaborate social network (e.g. spouse and children) to provide support. The negative correlations between diagnostic delay and the three social support scales could mean that social support is relatively short lived: initially strong, it probably wanes with the persistence of unexplained complaints.

\section{Reaction to diagnosis}

Responses to the interview questions "Did something change for you when it was established with certainty that you had SCCH?" and "Did you feel better or worse than before the diagnosis?" overlapped and were therefore combined. Twelve patients (23.1\%) felt better because "now there was clarity, it had a name, it was real", 11 patients $(21.2 \%)$ felt relief because treatment was possible and they could make adaptations, 5 patients $(9.6 \%)$ felt relief because it was nothing more serious such as cancer or rheumatoid arthritis, 9 patients (17.3\%) reported ambiguous feelings: they felt relief because of more clarity but also realized they had a chronic disease. Three patients (5.8\%) said they felt worse after the diagnosis was established, 2 patients (3.9\%) reported no change at all, and 10 (19.2\%) gave ambiguous answers containing positive and negative elements.

\section{Current condition}

\section{Clinical symptoms}

On the frontal-complaints-now drawing of the MPQDLV, the patients marked on average $7.12(\mathrm{SD}=9.43)$ grid cells; on the dorsal-complaints-now variable the mean was $5.23(\mathrm{SD}=8.04)$. In both cases these means were significantly higher $(t=2.152, p=.036$ and $t=$ $2.009, p=.05 ; d f=51$, resp.) than the means on frontalcomplaints-first and dorsal-complaints-first, suggesting a deterioration of symptoms over time.

Four patients $(7.7 \%)$ reported they never had pain, 13 patients $(25 \%)$ had pain that came in waves with symptom-free periods, in 32 patients $(61.5 \%)$ the pain was continuous but of variable intensity, and in 3 patients (5.8\%) pain was continuous with no difference in intensity. Mean scores and SDs of the visual analogue scales for present pain (VASnow), minimum pain (VASmin), and maximum pain (VASmax) were $35.50 \pm 27.41$, $18.54 \pm 17.87$, and $74.33 \pm 25.87$, respectively. These means, although higher, do not differ significantly from those of a Dutch sample [44] of 227 persons receiving physiotherapy for mobility problems (VASnow $=29.43$ \pm 22.64 , VASmin $=15.36 \pm 14.37$, VASmax $=67.17 \pm$ 23.82). In the present study, pain rating indices for the sensory (PRIS), affective (PRIA), and evaluative qualities (PRIE) of pain had means and SDs of $9.29 \pm 6.96,3.46$ $\pm 3.05,4.27 \pm 2.58$. The mean of the total pain rating index (PRIT) was $17.02 \pm 11.40$. Conservative $t$-tests using $d f=51$ showed that all means were significantly 
higher ( $p$-values.001, .0006, .021, and .0006, respectively) than the means of the patients undergoing physiotherapy reported in [44] (PRIS: $5.80 \pm 4.08$; PRIA: $1.83 \pm$ 1.97; PRIE: $3.37 \pm 1.74$; PRIT: $11.00 \pm 7.03$ ). These data suggest that the pain experienced by $\mathrm{SCCH}$ patients is similar or worse than the pain of the general, heterogeneous, population of individuals with usually painful mobility complaints who are treated by physiotherapy.

\section{Limitations and functioning}

Nineteen respondents (36.5\%) held jobs, 14 of whom (26.9\%) part-time. Ten respondents (19.2\%) were unemployed, $10(19.2 \%)$ were retired, and 13 patients (25\%) were on social benefits for permanent disability (regulated by Dutch national law). Among the $42 \mathrm{SCCH}$ patients who were either unemployed, worked part-time, or were on social benefits, 22 (42.3\% of the total) attributed this to their disease. This indicates that in a substantial number of cases $\mathrm{SCCH}$ is associated with debilitating limitations that affect the socio-economic situation of patients.

Table 4 contains the means, SDs, ranges, and Cronbach's alphas of the subscales of the SF20. Also shown are the means and SDs reported by Sonino et al. [45] of 86 patients with various forms of pituitary disease and 86 healthy respondents used as controls. ANOVAs yielded significant overall $F$-values (Table 4 ). Bonferroni comparisons using $\alpha=.05 / 3$ showed that all groups differed significantly from each other as regards physical functioning, health perceptions, and pain, with the $\mathrm{SCCH}$ patients having the least favorable scores. Regarding role functioning, the $\mathrm{SCCH}$ patients did not differ significantly from patients with pituitary disease but had significantly lower means than the healthy control group. The same pattern of results was obtained for social functioning and mental health. In sum, all means of the $\mathrm{SCCH}$ patients were significantly lower than those of the healthy group, and consistently lower (though not always statistically significant) than those of the pituitary patients.

\section{IIIness perceptions and disease acceptance}

Table 5 contains the means and SDs of the SCCH patients on the eight dimensions of the B-IPQ, as well as the means of two groups of patients (with type 2 diabetes and asthma) which were selected for comparison from a study by Broadbent et al. [46]. Type 2 diabetes and asthma are chronic conditions that can be relatively well-controlled by medication and personal life-style, though diabetes may have serious long-term complications. ANOVAs showed significant overall differences (Table 5) among the three patient groups on all B-IPQ variables except timeline. The latter result suggests that all groups were equally aware of the chronic nature of their diseases. Bonferroni comparisons with $\alpha=.05 / 3$ showed that as regards consequences (i.e. the perceived impact of one's illness) $\mathrm{SCCH}$ patients had significantly higher means than asthma patients but did not differ from patients with diabetes. A possible explanation is that diabetes and $\mathrm{SCCH}$ are conditions that are continuously present, whereas asthma usually manifests itself in acute exacerbations that are spaced in time. $\mathrm{SCCH}$ patients perceive lower personal and treatment control, and experience more physical complaints (the dimension "identity") than patients with asthma and diabetes. This probably reflects the fact that there is as yet no standard treatment for $\mathrm{SCCH}$ and that various applied

Table 4 Mean, SD, number of items, observed range, Cronbach's $\alpha$, and F-values of the SF20 scales observed in the present study and among patients and healthy controls in a comparison study (means with equal upper case superscripts are not significantly different)

\begin{tabular}{|c|c|c|c|c|}
\hline \multirow{2}{*}{$\begin{array}{l}\text { SF20-scale } \\
\text { (\# of items; observed range; } \alpha \text { ) }\end{array}$} & \multirow{2}{*}{$\begin{array}{l}\text { SCCH patients } \\
n=52\end{array}$} & \multicolumn{2}{|c|}{ Pituitary disease } & \multirow{2}{*}{$\begin{array}{l}\text { ANOVA } F \text {-value; } \\
d f=2,221\end{array}$} \\
\hline & & $\begin{array}{l}\text { Patients }^{c} \\
\mathrm{n}=86\end{array}$ & $\begin{array}{l}\text { Controls }^{c} \\
n=86\end{array}$ & \\
\hline $\begin{array}{l}\text { Physical functioning } \\
(6 ; 6-12 ; .673)\end{array}$ & $8.44^{\mathrm{A}} \pm 1.58$ & $26.6^{\mathrm{B}} \pm 3.7$ & $28.6^{C} \pm 2.1$ & $983.36^{* *}$ \\
\hline $\begin{array}{l}\text { Role functioning } \\
(2 ; 2-4 ; .766)\end{array}$ & $2.46^{\mathrm{A}} \pm .75$ & $2.8^{\mathrm{A}} \pm 1.5$ & $3.7^{\mathrm{B}} \pm .7$ & $25.237^{* *}$ \\
\hline $\begin{array}{l}\text { Social functioning } \\
(1 ; 1-6 ;-)\end{array}$ & $4.33^{\mathrm{A}} \pm 1.21$ & $4.8^{\mathrm{A}} \pm 1.7$ & $5.7^{B} \pm .7$ & $20.948^{* *}$ \\
\hline $\begin{array}{l}\text { Mental health }{ }^{\mathrm{a}} \\
(5 ; 5-30 ; .933)\end{array}$ & $21.61^{A} \pm 5.13$ & $22.8^{A, B} \pm 5.9$ & $24.6^{B} \pm 3.6$ & $6.417^{*}$ \\
\hline $\begin{array}{l}\text { Health perceptions }{ }^{a} \\
(5 ; 5-30 ; .745)\end{array}$ & $14.08^{\mathrm{A}} \pm 3.91$ & $19.6^{B} \pm 4.3$ & $22.8^{C} \pm 2.4$ & $95.857^{* *}$ \\
\hline $\begin{array}{l}\text { Pain }^{\mathrm{b}} \\
(1 ; 1-5 ;-)\end{array}$ & $3.63^{\mathrm{A}} \pm 1.27$ & $2.1^{B} \pm 1.2$ & $1.7^{C} \pm .8$ & $53.909^{* *}$ \\
\hline
\end{tabular}

${ }^{a}$ Higher values indicate better functioning and health. ${ }^{b}$ Higher values indicate more pain. ${ }^{c}$ Sonino et al. [45], the data of the Sonino et al. study were transformed to make them comparable to the means of the SCCH study. ${ }^{*} p<.002 .{ }^{* *} p<.00001$. 
Table 5 Means and SDs on the eight B-IPQ dimensions and two comparison samples (means with equal upper case superscripts are not significantly different)

\begin{tabular}{|c|c|c|c|c|}
\hline B-IPQ scale & $\begin{array}{l}\text { SCCH patients } \\
n=52\end{array}$ & $\begin{array}{l}\text { Asthma patients }^{\mathrm{a}} \\
\mathrm{n}=309\end{array}$ & $\begin{array}{l}\text { Diabetes } 2 \text { Patients } \\
\mathrm{n}=119\end{array}$ & $\begin{array}{l}\text { F-value }(p) \\
d f=2,477\end{array}$ \\
\hline Consequences & $5.63^{A} \pm 2.80$ & $3.5^{\mathrm{B}} \pm 2.3$ & $4.7^{\mathrm{A}} \pm 2.9$ & $21.575(<.0001)$ \\
\hline Timeline & $9.17 \pm 1.86$ & $8.8 \pm 2.2$ & $9.2 \pm 1.9$ & $1.920(.1478)$ \\
\hline Personal control & $5.31^{\mathrm{A}} \pm 2.35$ & $6.7^{B} \pm 2.4$ & $6.7^{B} \pm 2.3$ & $7.9729(.0004)$ \\
\hline Treatment control & $6.8^{A} \pm 2.37$ & $7.9^{B} \pm 2.0$ & $8.0^{B} \pm 2.3$ & $6.660(.0014)$ \\
\hline Identity & $6.21^{A} \pm 2.30$ & $4.5^{B} \pm 2.3$ & $4.6^{B} \pm 2.8$ & $11.153(<.0001)$ \\
\hline Concern & $4.77^{\mathrm{A}} \pm 3.26$ & $4.6^{A} \pm 2.8$ & $7.0^{B} \pm 3.1$ & $2.520(<.0001)$ \\
\hline Coherence & $6.15^{\mathrm{A}} \pm 2.54$ & $6.5^{\mathrm{A}} \pm 2.6$ & $7.9^{B} \pm 2.3$ & $15.222(<.0001)$ \\
\hline Emotional response & $4.04^{\mathrm{A}} \pm 3.21$ & $3.3^{\mathrm{A}} \pm 2.9$ & $4.3^{B} \pm 3.3$ & $5.192(.0059)$ \\
\hline
\end{tabular}

${ }^{a}$ Broadbent et al. [46].

treatments are only partially or not effective in controlling symptoms or disease progression. Life-style appears to have limited influence on symptomatology in $\mathrm{SCCH}$. Regarding coherence, concern, and emotional response, the $\mathrm{SCCH}$ patients did not differ from patients with asthma, but both groups had significantly lower means than the diabetes patients. This may be due to the fact that diabetes is a much better understood disease, treatment is well-established, and patients are well aware of its possible serious consequences if left untreated.

The patients answered several open questions concerning the acceptance for their illness by themselves and their social environment. Twenty-two patients (42.3\%) said they accepted their disease, 16 (30.8\%) accepted their disease but found it difficult to do so, and $12(23.1 \%)$ did not accept that they were ill. Two patients $(3.9 \%)$ gave contradictory responses. Twentyfour patients $(46.2 \%)$ considered it difficult to live with $\mathrm{SCCH}$, in 22 cases $(42.3 \%)$ because of the limitations caused by the illness and in two cases $(3.8 \%)$ because of anxiety and concern about the future. Twenty-eight patients $(53.8 \%)$ did not find it difficult to live with $\mathrm{SCCH}, 23$ (44.2\%) because they had learnt to adapt to their illness and 5 (9.6\%) because treatment was effective. Thirty-four respondents $(65.4 \%)$ reported that they experienced sufficient understanding for their illness in their environment, whereas $14(26.9 \%)$ reported insufficient understanding and 4 (7.7\%) felt only understood by their partner and the persons nearest to them. Thirty-six respondents (69.2\%) experienced no problems with the reactions of their environment; 4 patients (7.7\%) had experienced such problems in the past, and $12(23.1 \%)$ experienced problems in the present situation. Twelve respondents (23.1\%) had experienced problems in their jobs, with finding new jobs, or getting functions adapted to their limitations. Nine patients $(17.3 \%)$ had difficulties obtaining insurance or applying for social benefits.

\section{Relationships between pre-diagnostic and current conditions}

As the variables describing the pre-diagnostic condition and those concerning the present-day situation are numerous and internally collinear, data reduction was necessary before we could study their relationships meaningfully. Above, we already reported that the IES-R scales intrusion, avoidance, and hyperarousal can be summarized by their total (IES-R-total) and that the SSI scales can be represented by SSI-total without significant loss of information. In a similar way (i.e. principal component analysis) we found that the rating scales measuring despair, drama, concern, fright, and depression could be reduced to one factor that explained $76.4 \%$ of their variance. Scores on this factor were perfectly correlated with the sum of the five variables. Therefore, we have used this sum in our final analyses, and named it depressed-total, because depressed had the highest loading.

The SF20 subscales and the B-IPQ dimensions were submitted to principal component analysis and hierarchical cluster analysis to explore which scales could be joined. All SF20 scales except SFpain could be aggregated into one summary variable. We therefore computed the total of the first five SF20 subscales and labeled this new variable SF-general-health.

Among the B-IPQ dimensions, one new variable (BIPQ-impact) was constructed by summing consequence, identity, concern, and emotional response, as these variables had extensive communalities. We also summed the dimensions treatment control and coherence. As the latter variables suggest understanding of the disease, we labeled their sum BIPQ-cognition. Because timeline and personal control showed less association with the other BIPQ dimensions they were used separately in the analyses.

We performed multiple regression analyses with agefirst, frontal-complaints-first, dorsal-complaints-first, IESRtotal, SSItotal, depressed-total, and diagnostic delay 
as the predictors of frontal-complaints-now, dorsal-complaints-now, VASnow, VASmin, VASmax, PRIS, PRIA, PRIE, BIPQ-cognition, timeline, personal control, BIPQimpact, SFtotal, and SFpain, respectively. The results, listed in Table 6, show that all current condition variables except personal control can to some extent be predicted by one or more pre-diagnostic variables with statistical significance. Our data also show that all prediagnostic variables, except IES-R-total, contribute to one or more of the predictions. The most important predictors (in terms of number of contributions) are SSI-total, Age-first, Depressed-total, and dorsal-complaints-first. SSItotal has positive contributions to variables indicating favorable conditions (SFtotal and BIPQcognition) and contributes negatively to variables that express unfavorable aspects (frontal-complaintsnow, dorsal-complaints-now, VASnow, PRIA, and SFpain). Depressed-total has positive relations with the (unfavorable) VASmax, PRIA, and BIPQimpact, whereas it contributes negatively to the (favorable) SFtotal. The contributions of age-first and dorsal-first, are, however, more difficult to understand.

To clarify the above results, we performed a canonical correlation analysis (CANCOR) by means of SPSS MANOVA [47-49]. CANCOR investigates the relationships between two sets of variables by simultaneously looking for principal components in both sets under the restriction that the correlation between the first component in Set 1 and the first component in Set 2 is maximized. The same is required of the subsequent dimensions. The principal components (also called canonical axes or dimensions) can be interpreted by means of their loadings, that is, the correlations between the components and the original variables. Interpretation is often enhanced by graphs in which the components are represented by orthogonal dimensions and the variables by arrows whose coordinates on the dimension are given by the loadings.

In our case, the first set of variables consisted of agefirst, frontal-complaints-first, dorsal-complaints-first, SSItotal, IES-R-total, depressed-total, and diagnostic delay. The second set contained frontal-complaints-now, dorsal-complaints-now, VASnow, VASmin, VASmax, PRIS, PRIA, PRIE, BIPQ-cognition, timeline, personal control, BIPQ-impact, SFtotal, and SFpain. CANCOR yielded two components (canonical axes) with statistically significant correlations $\left(r_{1}=.911, p<.001 ; r_{2}=\right.$ $.830, p<.017)$. Figure 1 displays the loadings of the variables on the canonical axes.

The loadings of the current condition variables on the horizontal axis suggest that this dimension reflects apperceptions of health because the rightmost end is defined by SFtotal, i.e. general perceived health (higher scores denote better health), and the leftmost end by BIPQ-impact and PRIA, which measure negative affective reactions to illness and pain. The lower end of the vertical axis is defined by BIPQ-cognition and timeline. This possibly indicates that individuals with a better understanding of their illness and its treatment have clearer ideas about the chronic character of $\mathrm{SCCH}$.

Table 6 Multiple regression coefficients and standardized regression weights for predicting variables representing present-day conditions from variables representing pre-diagnostic aspects

\begin{tabular}{|c|c|c|c|c|c|c|c|c|}
\hline \multirow[b]{2}{*}{ Present-day variables (dependents) } & \multicolumn{8}{|c|}{ Pre-diagnostic variables (predictors) } \\
\hline & Age-first & Frontal-first & Dorsal-first & IESR-total & SSI-total & Depressed-total & Delay & $\mathbf{R}$ \\
\hline Frontal-now ${ }^{a}$ & - & $.304^{*}$ & $.323^{*}$ & - & $-.355^{* *}$ & - & - & $.647^{* *}$ \\
\hline Dorsal-now ${ }^{b}$ & - & . & $627^{* *}$ & - & $-.428^{* *}$ & - & - & $.738^{* *}$ \\
\hline VASnow ${ }^{c}$ & - & - & - & - & $-.296^{*}$ & - & - & $.296^{*}$ \\
\hline$V_{A S m i n}{ }^{d}$ & - & - & - & - & - & - & $.413^{* *}$ & $.413^{* *}$ \\
\hline VASmax & - & - & - & - & - & $.418^{* *}$ & - & $.418^{* *}$ \\
\hline $\mathrm{PRIS}^{f}$ & $-.428^{* *}$ & - & - & - & - & - & - & $.428^{* *}$ \\
\hline$P R I A^{g}$ & - & - & $.255^{*}$ & - & $-.252^{*}$ & $.543^{* *}$ & - & $.722^{* *}$ \\
\hline PRIE ${ }^{\mathrm{h}}$ & $-.355^{*}$ & - & - & - & - & - & - & $.355^{*}$ \\
\hline SFpain ${ }^{i}$ & - & - & - & - & $-.284^{*}$ & - & - & $.284^{*}$ \\
\hline SFtotal & - & - & - & - & $387^{* *}$ & $-.404^{* *}$ & - & $.653^{* *}$ \\
\hline BIPQimpact ${ }^{k}$ & $-.243^{*}$ & - & - & - & & $.619^{* *}$ & - & $.730^{* *}$ \\
\hline BIPQcognition' & $-.317^{*}$ & - & $-.447^{* *}$ & - & $.332^{*}$ & - & - & $.510^{* *}$ \\
\hline Timeline & $-.369^{* *}$ & - & - & - & - & - & - & $.369^{* *}$ \\
\hline Personal control & - & - & - & - & - & - & - & - \\
\hline
\end{tabular}

${ }^{\mathrm{a}}$ Frontal-now = frontal area indicated as presently painful; ${ }^{\mathrm{b}}$ Dorsal-now = dorsal area indicated as presently painful; ${ }^{\mathrm{C}} \mathrm{VASnow}=\mathrm{visual}$ analogue scale score of present pain; ${ }^{d}$ VASmin = visual analogue scale score of minimal pain; ${ }^{e}$ VASmax = visual analogue scale score of maximal pain; ${ }^{f} P R I S=M P Q$ pain rating index

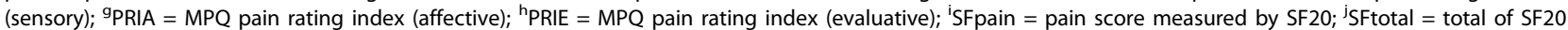
subscales physical functioning, role fulfillment, social functioning, mental health, and perceived health; ${ }^{\mathrm{k}} \mathrm{BIPQimpact}=$ sum of BIPQ consequence, identity, concern, and emotional response; 'BIPQcognition = sum of BIPQ treatment control and coherence. 
Those individuals have currently lower scores on VASnow and frontal- and dorsal-complaints-now.

The loadings of the pre-diagnostic variables confirm our interpretation of the horizontal axis: its left extreme is defined by depressed-total and IES-R-total, variables which measure strong affects. Thus, strong negative feelings in the pre-diagnostic period are associated with strong negative affects at the time of the interview. The high positive loadings of SSI-total on Axis 1 show that social support may counteract such negative affects. The direction of SSI-total explains its role in the regression analyses: it runs into the same direction as the favorable SFtotal and BIPQcognitions, and in the opposite direction of the unfavorable frontal-now, dorsal-now, VASnow, and PRIA. Depressed-total has high loadings on the unfavorable end of Axis 1, which explains its positive weights in the prediction of BIPQimpact, PRIA, and VASmax and its negative weight in predicting SFtotal.
Although IES-R-total loads highly on the negative end of Axis 1, it played no role in any of the regression analyses. Figure 1 shows why: IES-R-total, depressed-total, and SSI are strongly interrelated (collinear) and cannot therefore be entered together in a regression analysis. The larger loadings of SSI-total and depressed-total explain their precedence over IES-R-total.

The second axis has high loadings of frontal-complaints-first and age-first, that is, patients with more anterior (chest wall) complaints and those who were older at the onset of SCCH tend to have higher scores on VASnow and on frontal-complaints-now at a later date. Interestingly, frontal-complaints-now and dorsalcomplaints-now have higher (negative) loadings on the first axis than on the second axis. This means that these 'objective' indicators of $\mathrm{SCCH}$ in the present situation are also associated with affective reactions in the past.

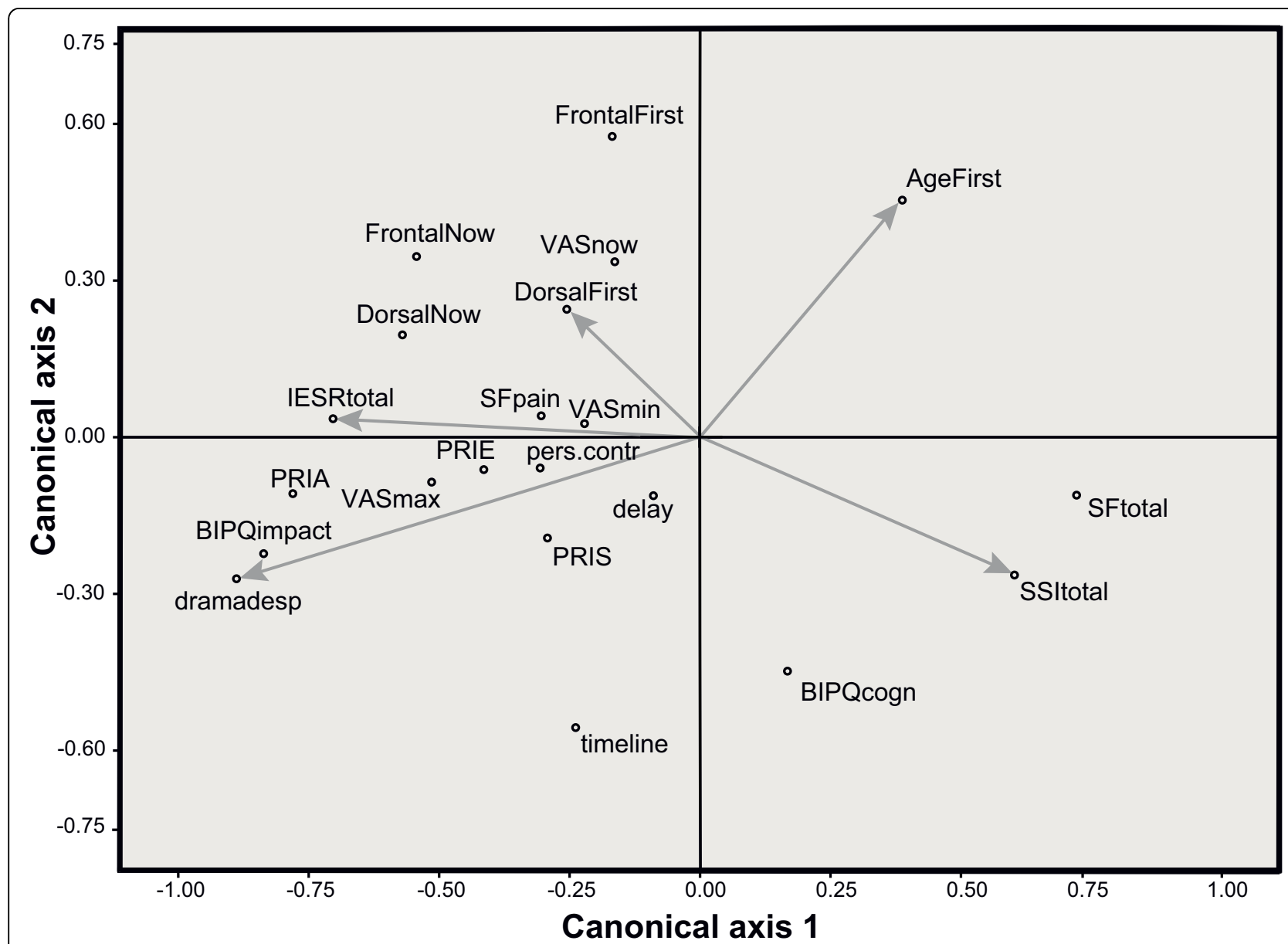

Figure 1 Loadings of pre-diagnostic variables and present-day variables on two canonical axes. Each variable is a vector in the canonical space; for legibility we have only drawn vectors for the pre-diagnostic variables. Vector lengths indicate their importance in the relationship between the two sets of variables. 


\section{Discussion}

The above results consistently indicate that the average patient with $\mathrm{SCCH}$ experienced serious psychological problems both in the current situation at the time of the interview and in the pre-diagnostic period between first manifestations of the disease and establishment of the diagnosis of SCCH. With respect to the pre-diagnostic period, patients reported affect and behavior that classify as PTS symptoms. Comparisons with reference groups made it clear that $\mathrm{SCCH}$ patients had significantly higher scores on measures of PTS than women who had experienced pregnancy termination because of fetal abnormality, and women three months after childbirth $[28,32]$. We speculate that the traumatic experiences of having an unwanted abortion, however sad, or giving birth, however violent, have a shorter duration than being victim of an as yet unexplained and thus untreatable illness, which can be construed as a chronic stressor. It should be noted here, that the IES-R questionnaire we used, measures PTS symptoms, and does not yield a formal PTSD diagnosis. Although some authors would argue that serious physical illness does not meet the current DSM-IV definition of a traumatic event, the present study is in line with others that have documented elevated levels of PTS after breast cancer [22-24], bone marrow transformation for cancer [25], and acute medical treatment in Intensive Care Units [26]. Regardless of the exact demarcation of the trauma concept, the present study demonstrates that our SCCH patients reported elevated levels of intrusion, avoidance, and hyperarousal symptoms in response to their illness.

$\mathrm{SCCH}$ patients reported fair to good social support during the pre-diagnostic period. We found that support was greater in patients who were older during the prediagnostic interval, which is possibly explained by the fact that older persons have more stable and more intimate social networks, which stood the test of time. We also found that social support was inversely related to diagnostic delay, indicating that this form of support may diminish as the unexplained illness lasts longer. Our expectation that social support would have a beneficial effect on PTS was indeed confirmed, although the correlation found was very weak.

$\mathrm{SCCH}$ patients reported equal or more pain in their current situation than a comparison group of patients treated with physiotherapy for (painful) mobility complaints [44]. They also reported more pain and poorer physical functioning than patients with pituitary disease [45]. Physical, social, and role functioning, as well as pain and perceived physical and mental health were consistently worse in $\mathrm{SCCH}$ patients than in healthy controls [45]. Illness perceptions were comparable to those of patients with asthma and type 2 diabetes, with various significant differences which indicated that patients were aware of important aspects of their particular illnesses.

We have demonstrated significant associations between data reported about the pre-diagnostic period and responses concerning the situation at the time of the interview. Strong perceptions and feelings about one's health (i.e. PTS symptoms, despair, drama, concern, fear, and depression) in the pre-diagnostic period are related to negative health apperceptions in the present time.

Diagnostic delay was found to be negatively related to social support and positively related to minimum pain. In a recent publication [3] we established that, when controlling for age, diagnostic delay was also positively related to maximum pain, affective pain rating (PRIA), the BIPQ scales emotions and consequences, and unemployment/disability. Diagnostic delay was also negatively related to the SF20-scales role fulfillment and social functioning, and hours worked per week.

Because our study is retrospective with regard to the pre-diagnostic period, which for some patients occurred many years previously, it is possible that some or many respondents had no accurate recall of their physical and psychological conditions at that stage. This could represent two types of problems. First, the responses to the prediagnostic questions may contain random components that could be relatively large, leading to low reliability and lower correlations (attenuation). Since we obtained many sizeable correlations among the pre-diagnostic variables and between the latter and some of the present-day variables, this possible attenuation problem has not prevented us from finding some interesting relationships. However, it is still possible that unreliability may have precluded the discovery of additional interesting or important relationships. A second possibility is that respondents colored their responses to the pre-diagnostic questions on the basis of their present feelings and cognitions. Patients who felt better (worse) now might tend to report more (un) favorably about their past condition. In that case we would expect many (very) high correlations among most of the variables concerning the pre-diagnostic period. Indeed, we did find several high correlations, for example, within the scales measuring PTS and within those measuring social support, but not between those sets of variables. We also found that feelings of worry, fright, drama, concern, and depression could be reduced to one dimension, but this dimension did not have extremely high correlations with other pre-diagnostic variables. We can therefore conclude that potential retrograde coloring of responses did not seriously influence our results. We would like to stress that prospective research into the effects of pre-diagnostic conditions on later illness experience is practically impossible in the case of rare diseases such as $\mathrm{SCCH}$. 
As the pre-diagnostic variables were measured simultaneously with the present-day variables, we cannot be certain that the associations found between both sets imply that the present-day condition is caused or influenced by the pre-diagnostic situation. Nevertheless, the arguments presented above and the general results suggest that such an influence is probable.

\section{Conclusions}

$\mathrm{SCCH}$ is an illness with serious consequences both in the pre-diagnostic period and after the diagnosis is established. SCCH patients reported relatively strong PTS symptoms, several unfavorable illness and health status perceptions, impaired quality of life, and considerable pain. Moreover, negative psychological states and lack of social support in the pre-diagnostic interval predict negative feelings and cognitions long after the diagnosis has been established. This implies that health care professionals should be alert for stress and other psychological problems of patients with unexplained chronic complaints as long as a diagnosis is not established, and that extensive efforts should be made to shorten this period.

\section{Acknowledgements}

We gratefully acknowledge the additional information provided by Dr. François Faurisson of Eurordis, France, Dr. Nicoletta Sonino of Padua University, and Dr. Korenromp and Dr. Mulder of Utrecht University Medical Center. We also express our gratitude for the support from the Netherlands Association of Patients with Sternocostoclavicular Hyperostosis.

\section{Author details \\ ${ }^{1}$ Institute of Psychology, Leiden University, The Netherlands. ${ }^{2}$ Department of Endocrinology and Metabolic Diseases, Leiden University Medical Center (LUMC), The Netherlands. ${ }^{3}$ Department of Clinical Psychology, University of Amsterdam, The Netherlands. ${ }^{4}$ Unit of Psychology, Leiden University Medical Center (LUMC), The Netherlands.}

\section{Authors' contributions}

WAVDK initiated and coordinated the study. NATH, AAK, WAVDK, AAPVE, and LCSH are responsible for its design. SAC, LCSH, and FMCDD collected the data. SAC, LCSH, FMCDD and WAVDK analyzed the data. WAVDK drafted the manuscript and all authors contributed to its critical revision. All authors read and approved the final version.

\section{Authors' information}

WAVDK is presently the chairman of the Netherlands Association of Patients with Sternocostoclavicular Hyperostosis.

\section{Competing interests}

The authors declare that they have no competing interests.

Received: 4 February 2010 Accepted: 9 September 2010

Published: 9 September 2010

\section{References}

1. EURORDIS: The voice of 12,000 patients: Experiences and expectations of rare disease patients on diagnosis and care in Europe. France: EURORDIS 2009.

2. Editorial: Listening to patients with rare diseases. The Lancet 2009, 373:868.
3. Van der Kloot WA, Chotkan SA, Kaptein AA, Hamdy NAT: Diagnostic delay in sterno-costo-clavicular hyperostosis: Impact on various aspects of quality of life. Arthritis Care Res 2010, 62:251-257.

4. Sonozaki H, Furasowa S, Seki H, Kurosawa T, Tateishi A, Kabata K: Four cases with symmetrical ossifications between the clavicles and the first ribs on both sides. Kanto J Orthop Traumatol 1974, 5:244-247.

5. Köhler H, Uehlinger E, Kutzner J, Weihrauch TR, Wilbert L, Schuster R: Sterno-kosto-klavikuläre Hyperostose: Ein bisher nicht beschriebenes Krankheitsbild [Sterno-costo-clavicular hyperostosis: A not yet described disorder]. Dtsch Med Wochenschr 1975, 100:1519-1523, 1535-1536.

6. Chamot AM, Benhamou CL, Kahn MF, Beeraneck L, Kaplan G, Prost A: Le syndrome Acné Pustulose Hyperostose Ostéite (SAPHO): Résultats d'une enquête nationale 85 observations [The syndrome of Acne Pustulosis Hyperostosis Osteitis (SAPHO): Results of a national survey with 85 observations. Rev Rhum 1987, 54:187-196.

7. Freyschmidt J, Sternberg A: The bullhead sign: scintigraphic pattern of sternocostoclavicular hyperostosis and pustulotic arthroosteitis. Eur Radiol 1998, 8:807-812.

8. Jahangier ZN, Jacobs JWG, Bijlsma JWJ: SAPHO-syndroom: gemeenschappelijke noemer voor enkele bot- en huidziekten [SAPHO syndrome: common denominator for some bone and skin diseases]. Ned Tijdschr Geneeskd 1997, 141:764-769.

9. Kalke S, Perera SD, Patel ND, Gordon TE, Dasgupta B: The sternoclavicular syndrome: Experience from a district general hospital and results of a national postal survey. Rheumatology 2001, 40:170-177.

10. Taylor HG, Dawes PT: Sterno-costo-clavicular hyperostosis. Brit I Clin Pract 1992, 46:276-278.

11. Hayem G: Valuable lessons from SAPHO syndrome. Joint Bone Spine 2007, 74:123-126.

12. Kasperczyk A, Freyschmidt J: Pustulotic arthroosteitis: Spectrum of bone lesions with palmoplantar pustuslosis. Radiology 1994, 191:207-211.

13. Sartoris DJ, Schreiman JS, Kerr R, Resnik CS, Resnick D: Sternocostoclavicular hyperostosis: A review and report of 11 cases. Radiology 1986, 158:125-128.

14. Van Doornum S, Wicks I, Barraclough D, McColl G: SAPHO: rare or just not recognized? Semin Arthritis Rheum 2000, 30:70-77.

15. Miyamoto M, Shirai Y, Nakayama Y, Gembun Y, Kitagawa Y, Nanbu A: A case report of Synovitis Acne Pustulosis Hyperostosis and Osteitis Syndrome presenting with Spondylodiscitis. J Nipp Med Sch 2000, 67:191-197.

16. Davies AM, Marino AJ, Evans N, Grimer RJ, Deshmukh N, Mangham DC: SAPHO-syndrome: 20-year follow-up. Skel Radiol 1999, 28:159-162.

17. Tehlirian C: Synovitis-Acne-Pustulosis-Hyperostosis-Osteitis (SAPHO). Johns Hopkins Rheumatology Rounds Online: Rounds 72006 [http://www.hopkinsarthritis.org/physician-corner/cme/rheumatology-rounds/ sapho_rheumrounds7.html].

18. Nettleton S, Watt I, O'Malley L, Duffey P: Understanding the narratives of people who live with medically unexplained illness. Patient Educ Couns 2005, 56:205-210.

19. Brewin $C R$, Andrews B, Rose $S$, Kirk M: Acute stress disorder and posttraumatic stress disorder in victims of violent crime. Am J Psychiatry 1999, 156:360-366

20. Ford JD, Campbell KA, Storzbach D, Binder LM, Kent Anger W, Rohlman DS: Posttraumatic stress symptomatology is associated with unexplained illness attributed to Persian Gulf War military service. Psychosom Med 2001, 63:842-849.

21. Jankowsi K: PTSD and physical health. United States Department of Veterans Affairs, National Center for Posttraumatic Stress Disorder[http:// www.ptsd.va.gov/professional/pages/ptsd-physical-health.asp].

22. Green BL, Rowland JH, Krupnick JL, Epstein SA, Stockton P, Stern NM, Spertus IL, Steakley C: Prevalence of posttraumatic stress disorder in women with breast cancer. Psychosomatics 1998, 39:102-111.

23. Naidich JB, Motta RW: PTSD-related symptoms in women with breast cancer. J Psychother Indep Pract 2000, 1:35-54.

24. Pitman RK, Lanes DM, Williston SK, Guillaume JL, Metzger LJ, Gehr GM, Orr SP: Psychophysiologic assessment of posttraumatic stress disorder in breast cancer patients. Psychosomatics 2001, 42:133-140.

25. Jacobsen PB, Sadler IJ, Booth-Jones M, Soety E, Weitzner MA, Fields KK: Predictors of posttraumatic stress disorder symptomatology following bone marrow transplantation for cancer. J Consult Clin Psychol 2002. 70:235-240. 
26. Boer KR, Van Ruler O, Van Emmerik AAP, Sprangers MA, De Rooij SE Vroom MB, De Borgie CAJM, Boermeester MA, Reitsma JB, The Dutch Peritonitis Study Group: Factors associated with posttraumatic stress symptoms in a prospective cohort of patients after abdominal sepsis: a nomogram. Intensive Care Medicine 2008, 34:664-674

27. Engelhard IM, Van den Hout MA, Arntz A: Posttraumatic stress disorder after pregnancy loss. Gen Hosp Psychiat 2001, 23:62-66.

28. Korenromp MJ, Christiaens GCM, Van den Bout J, Mulder EJH, Hunfeld JAM, Bilardo CM, Offermans JPM, Visser GHA: Long-term psychological consequences of pregnancy termination for fetal abnormality: A crosssectional study. Prenat Diagn 2005, 25:253-260.

29. Van Emmerik AAP, Kamphuis JH, Emmelkamp PMG: Prevalence and prediction of re-experiencing and avoidance after elective surgical abortion: A prospective study. Clin Psychol Psychother 2008, 15:378-385.

30. Reynolds JL: Post-traumatic stress disorder after childbirth: the phenomenon of traumatic birth. Can Med Assoc J 1997, 156:831-835.

31. Söderquist J, Wijma B, Thorbert G, Wijma K: Risk factors for pregnancy in post-traumatic stress and depression after childbirth. Brit J Obstet Gynecol 2009, 116:672-680.

32. Olde E, Kleber RJ, Van der Hart O, Pop VJM: Childbirth and posttraumatic stress responses: A validation study of the Dutch Impact of Event Scale Revised. Eur J Psychol Asses 2006, 22:259-267.

33. Brewin CR, Andrews B, Valentine JD: Meta-analysis of risk factors for posttraumatic stress disorder in trauma-exposed adults. $J$ Consult Clin Psychol 2000, 68:748-766.

34. Cluver L, Fincham DS, Seedat S: Posttraumatic stress in AIDS-orphaned children exposed to high levels of trauma: The protective role of perceived social support. J Trauma Stress 2009, 22:106-112.

35. Dirkzwager A, Bramsen I, Van der Ploeg H: Social support, coping, life events, and posttraumatic stress symptoms among former peacekeepers: A prospective study. Pers Indiv Differ 2003, 34:1545-1559.

36. Kamphuis $\mathrm{JH}$, Emmelkamp PMG, Bartak A: Individual differences in posttraumatic stress following post-intimate stalking: Stalking severity and psychological variables. Brit J Clin Psychol 2003, 42:145-156.

37. White-Williams C, Grady KL, Wang EC, Naftel DC, Rybarczyk B, Young JB, Pelegrin D, Myers S, Kirklin J, Czerr J, Kobashigawa J, Chait J, Heroux A, Higgins R: The relationship of social support and quality of life 5 to 10 years after heart transplantation [abstract]. J Heart Lung Transp/ 2009, 28: S128.

38. Zheng Y, Ye DQ, Pan HF, Li WX, Li LH, Li J, Li XP, Xu JH: Influence of social support on health-related quality of life in patients with systemic lupus erythematosus. Clin Rheumatol 2009, 28:265-269.

39. Van der Kloot WA, Vertommen $\mathrm{H}$, (Eds): De MPQ-DLV, een standaard nederlandstalige versie van de McGill Pain Questionnaire: Achtergronden en handleiding [The MPQ-DLV, a standard Dutch language version of the McGill Pain Questionnaire: Background and instructions] Lisse, The Netherlands: Swets \& Zeitlinger 1989.

40. Kleber RJ, de Jong E: Dutch version of the Impact of Event Scale revised. Internal report Utrecht University, The Netherlands, Department of Clinical Psychology 1989.

41. Timmerman IGH, Emanuels-Zuurveen ES, Emmelkamp PMG: The Social Support Inventory (SSI): A brief scale to assess perceived adequacy of social support. Clin Psychol Psychoth 2000, 7:401-410.

42. Kaptein A, Van Korlaar IM, Scharloo M: De IPQ-K [the Brief IIIness Perception Questionnaire]. 2004 [http://www.uib.no/ipq].

43. Kempen GIJM, Brilman El, Heyink JW, Ormel J: Het meten van de algemene gezondheidstoestand met de MOS Short-Form General Health Survey (SF-20) [measuring general health by the MOS Short-Form General Health Survey (SF-20)]. Groningen University, The Netherlands, Noordelijk Centrum voor Gezondheidsvraagstukken 1995

44. Kraaijenoord E, Van der Kloot WA: Pijnmeting met de MPQ-DLV: een kijkje in de data [Pain measurement with the MPQ-DLV: a look at the data]. Leiden Psychological Reports, PRM 97-03 Leiden University, The Netherlands, Department of Psychology 1997.

45. Sonino N, Ruini C, Navarrini C, Ottolini F, Sirri L, Paoletta A, Fallo F, Boscaro M, Fava GA: Psychosocial impairment in patients treated for pituitary disease: a controlled study. Clin Endocrinol 2007, 67:719-726.

46. Broadbent E, Petrie K, Main J, Weinman J: The Brief Illness Perception Questionnaire. J Psychosom Res 2006, 60:631-637.

47. SPSS Data Analysis Examples. Canonical Correlation Analysis. [http:// www.ats.ucla.edu/stat/spss/dae/canonical.htm]
48. Stevens J: Applied multivariate statistics for the social sciences Hillsdale, New Jersey: Erlbaum, 42009.

49. Tabachnik BG, Fidell LS: Using multivariate statistics Boston: Allyn \& Bacon, 5 2007

doi:10.1186/1477-7525-8-97

Cite this article as: van der Kloot et al:: The psychological burden of an initially unexplained illness: patients with sternocostoclavicular hyperostosis before and after delayed diagnosis. Health and Quality of Life Outcomes 2010 8:97.

\section{Submit your next manuscript to BioMed Central and take full advantage of:}

- Convenient online submission

- Thorough peer review

- No space constraints or color figure charges

- Immediate publication on acceptance

- Inclusion in PubMed, CAS, Scopus and Google Scholar

- Research which is freely available for redistribution

Submit your manuscript at www.biomedcentral.com/submit
Ciomed Central 